\title{
Warfarin and fibrinolysis - a challenging combination: an observational cohort study
}

\author{
Sini Saarinen ${ }^{1 *+}$, Jyrki Puolakka ${ }^{1 \dagger}$, James Boyd ${ }^{1+}$, Taneli Väyrynen ${ }^{2 \dagger}$, Harri Luurila ${ }^{3 \dagger}$ and Markku Kuisma ${ }^{1 \dagger}$
}

\begin{abstract}
Background: Patients presenting with ST-segment elevation myocardial infarction (STEMI) frequently use warfarin. Fibrinolytic agents and warfarin both increase bleeding risk, but only a few studies have been published concerning the bleeding risk of warfarin-prescribed patients receiving fibrinolysis. The objective of this study was to define the prevalence for intracranial haemorrhage $(\mathrm{ICH})$ or major bleeding in patients on warfarin treatment receiving pre-hospital fibrinolysis.

Methods: This was an observational cohort study. Data for this retrospective case series were collected in Helsinki Emergency Medical Service catchment area from 1.1.1997 to 30.6.2010. All warfarin patients with suspected STsegment elevation myocardial infarction (STEMI), who received pre-hospital fibrinolysis, were included. Bleeding complications were detected from Medical Records and classified as ICH, major or minor bleeding.

Results: Thirty-six warfarin patients received fibrinolysis during the study period. Fourteen patients had bleeding complications. One (3\%, 95\% Cl 0-15\%) patient had ICH, six (17\%, 95\% Cl 7-32\%) had major and seven (19\%, 95\% Cl 9-35\%) had minor bleeding. The only fatal bleeding occurred in a patient with ICH. Patients' age, fibrinolytic agent used or aspirin use did not predispose to bleeding complications. High International Normalized Ratio (INR) seemed to predispose to bleedings with values over 3, but no statistically significant difference was found.
\end{abstract}

Conclusions: Bleedings occur frequently in warfarin patients treated with fibrinolysis in the real world setting, but they are rarely fatal.

\section{Background}

Pre-hospital fibrinolysis is an effective alternative in the treatment of acute ST-segment elevation myocardial infarction (STEMI). Reduced time delay from the onset of symptoms to fibrinolysis is related to reduced mortality $[1,2]$. Many patients presenting with STEMI also have other diseases, such as atrial fibrillation or severe heart failure, requiring oral anticoagulants for the prevention of thromboembolic complications. Guidelines of European Society of Cardiology, American College of Cardiology (ACC) and American Heart Association (AHA) consider the use of oral anticoagulants as a relative contraindication for fibrinolysis [3-5]. The most threatening complication associated with both warfarin and fibrinolytic agents is an intracranial or a major bleeding, which

\footnotetext{
* Correspondence: sini.saarinen@hus.fi

+ Contributed equally

${ }^{1}$ Helsinki Emergency Medical Service System, Helsinki University Central

Hospital, PL 112, 00099 Helsinki City, Helsinki, Finland

Full list of author information is available at the end of the article
}

can be fatal. These patients are frequently transported directly to primary percutaneous coronary intervention (PCI). According to the guidelines, fibrinolysis should, however, be considered if PCI cannot be performed within 90-120 minutes when emergency medical service (EMS) meets the patient [3-5]. Additionally, the information on prior warfarin usage is not always available, especially in patients who are resuscitated from sudden out-of-hospital cardiac arrest.

Even though bleeding associated with fibrinolysis has been carefully investigated, only a few studies have been done concerning patients on oral anticoagulants receiving fibrinolysis. The aim of this study was to report the prevalence of serious haemorrhages with patients on oral anticoagulants receiving pre-hospital fibrinolysis for suspected STEMI.

\section{Methods}

This was an observational cohort study approved by Institutional Review Board of Helsinki University Central

\section{() Biomed Central}


Hospital. The study plan was retrospective, but data was collected prospectively for Fibrinolysis Registry in Helsinki EMS area during 1.1.1997-30.6.2010. Helsinki is the capital city of Finland with 584000 inhabitants. The EMS consists of seven to eight basic life support (BLS) -units, four advanced life support (ALS) -units, a medical supervisor unit and a physician staffed mobile intensive care unit (MICU). The medical supervisor unit and the MICU are provided with fibrinolytic agents.

All patients on warfarin were included, if they received out-of-hospital fibrinolysis for suspected STEMI during the study period. Unlike many other studies concerning bleeding complications, this was a "real world setting" study including all patients despite their age, bleeding risk or clinical condition. The decision to initiate fibrinolysis for suspected STEMI was made by an emergency physician, either on scene or after consultation with 12lead electrocardiogram (ECG) transmission. Emergency physicians in Helsinki EMS filled a detailed documentation form for Fibrinolysis Registry after each pre-hospital fibrinolysis. All patients receiving fibrinolysis for suspected STEMI or pulmonary embolism are included in the Fibrinolysis registry of Helsinki EMS, as well as patients with suspected STEMI receiving other treatment than fibrinolysis (i.e. primary PCI). Only patients receiving fibrinolysis for suspected STEMI were included in the study. STEMI diagnose was not confirmed from Hospital Medical Records. Therefore it is possible some patients received fibrinolysis inappropriately not actually suffering from STEMI. However, a physician responsible for maintaining the registry checked correctness of indications for fibrinolysis and ECG diagnostics in all cases.

One of the authors (J.P) investigated the Medical Records of receiving hospitals to detect possible complications after fibrinolysis. Reported laboratory tests were drawn on arrival to hospital. Bleeding complications were classified as intracranial haemorrhage (ICH), major and minor bleeding. ICH was diagnosed by computer tomography $(\mathrm{CT})$ scan or as an autopsy finding. Major bleeding was defined as a haemorrhage causing a need for a blood-transfusion, all other bleedings reported in Medical Records were defined as minor. Time from fibrinolysis to bleeding, blood units transfused and treatment of bleeding were also registered.

Statistical analysis was performed using SPSS for Windows V18.0 Software (SPSS Inc, Chicago, IL, USA). ChiSquare test (Fisher's Exact Test) was used for categorical variables and Mann-Whitney U test for continuous variables with non-normal distribution. Median values were reported with 25th-75th percentiles and proportions with $95 \%$ confidence intervals (95\% CI) according to the Agresti-Coull method. For statistical analysis ICH and major bleeding groups were compared to minor and nobleeding groups. These two groups were chosen to be compared on the basis of clinical relevance.

\section{Results}

\section{Study population}

Altogether 1322 pre-hospital fibrinolysis for suspected STEMI were given during the study period. The study population consisted of 36 warfarin treated patients, whose baseline characteristics are shown in Table 1. Eighty three percent (95\% CI 68-93\%) of study patients were treated with fibrinolysis before year 2005. Chest pain was the most common presenting symptom ( $\mathrm{n}=$ $24 ; 67 \%, 95 \%$ CI $50-80 \%)$. The main location of STsegment elevation was anterior wall in 18 (50\%, 95\% CI 34-66\%), inferior wall in 15 (42\%, 95\% CI 27-58\%) and lateral wall in $3(8 \%, 95 \%$ CI $2-23 \%)$ patients. Median time from the onset of the symptoms to fibrinolysis was $68 \mathrm{~min}$ (IQR 49-113 min), while median time from emergency call to fibrinolysis was $51 \mathrm{~min}$ (IQR 36-60 min). Other contraindications for fibrinolysis than warfarin existed with four $(11 \%, 95 \%$ CI 4 $26 \%)$ patients. Those were malignancy, hypertension and previous $\mathrm{ICH}$.

Table 1 Baseline characteristics of study patients $(n=36)$

\begin{tabular}{|c|c|}
\hline $\mathrm{n}(\%, 95 \% \mathrm{Cl})$ & \\
\hline Age (years)* & $70(62-78)$ \\
\hline Sex; men & $28(78 \%, 62-89 \%)$ \\
\hline \multicolumn{2}{|l|}{ Previous medical history } \\
\hline ischaemic heart disease & $21(58 \%, 42-73 \%)$ \\
\hline hypertension & $24(67 \%, 50-80 \%)$ \\
\hline diabetes & $11(31 \%, 18-47 \%)$ \\
\hline myocardial infarction & 17 (47\%, 32-63\%) \\
\hline thrombolysis & $9(25 \%, 14-41 \%)$ \\
\hline $\mathrm{PCl}$ or $\mathrm{CABG}$ & $5(14 \%, 6-29 \%)$ \\
\hline use of aspirin & $2(6 \%, 1-19 \%)$ \\
\hline \multicolumn{2}{|l|}{ Signs before fibrinolysis } \\
\hline cardiac arrest & $10(28 \%, 16-44 \%)$ \\
\hline pulmonary oedema & $1(3 \%, 0-15 \%)$ \\
\hline cardiogenic shock & $5(14 \%, 6-29 \%)$ \\
\hline \multicolumn{2}{|l|}{ Warfarin } \\
\hline prior use known before fibrinolysis & $34(94 \%, 81-99 \%)$ \\
\hline \multicolumn{2}{|l|}{ indication } \\
\hline atrial fibrillation & $20(55.5 \%, 40-70 \%)$ \\
\hline cerebrovascular disease & $6(17 \%, 7-32 \%)$ \\
\hline pulmonary embolism & $1(3 \%, 0-15 \%)$ \\
\hline deep vein thrombosis & $2(5.5 \%, 1-19 \%)$ \\
\hline heart valve disease & $3(8 \%, 2-23 \%)$ \\
\hline cardiomyopathy & $4(11 \%, 4-26 \%)$ \\
\hline
\end{tabular}

* = median (IQR). PCI = Percutaneous Coronary Intervention, CABG = Coronary Artery Bypass Graft Surgery. 


\section{Medication}

Four fibrinolytic agents were used: streptokinase 19972002, alteplase (tPA) 1997, reteplase 1998-2007 and tenecteplase 2008-2010 (Table 2). As adjuvant medication, aspirin $250 \mathrm{mg}$ and/or unfractionated (UFH) or low molecular weight heparin (LMWH) were used (Table 2). UHF was given $5000 \mathrm{IU}$ as a bolus and continued with infusion $1000 \mathrm{IU} / \mathrm{h}$. LMWH was enoxaparine, which was given $30 \mathrm{mg}$ intravenously and $1 \mathrm{mg} / \mathrm{kg}$ subcutaneously or only subcutaneously or intravenously. UFH was replaced by LMWH after year 1999.

\section{Laboratory test values}

On arrival to hospital, INR varied from 1.6 to 5.8. Median INR value was higher with $\mathrm{ICH} /$ major bleeding group compared to minor and no-bleeding groups (Figure 1). Median haemoglobin and thrombocyte count values are shown in Table 2.

\section{Bleeding complications}

Bleeding complication occurred in 14 (39\%, 95\% CI $25-55 \%$ ) patients, of whom only one had a bleeding before hospital admission. Median time from fibrinolysis to bleeding was $22 \mathrm{~h}$ (IQR 6-47 h). Major bleeding occurred in $6(17 \%, 95 \%$ CI $7-32 \%)$ patients and $\mathrm{ICH}$ in one patient $(3 \%, 95 \%$ CI $0-15 \%)$. The site of major bleeding was gastrointestinal in 3 (50\% of major bleedings) patients, unknown in 2 and pharynx in one. In addition to gastrointestinal bleeding, haemothorax was diagnosed in one patient. Major-bleeding patients received on median 4 units of packed red blood cells. The sites of minor bleeding were puncture site, urinary or respiratory tract or ocular angle.

\section{Statistical findings}

Statistically significant differences between ICH or major bleeding - and minor or no-bleeding groups on age, gender, blood pressure before fibrinolysis or heparin/ LMWH use were not found. Warfarin patients who were medicated with aspirin prior to fibrinolysis, had less bleedings than those who did not receive aspirin ( $\mathrm{p}$ $=0.037$ ). Reteplase and tenecteplase use did not cause significantly less serious bleedings compared to other

Table 2 Comparison between patients with major bleeding or $\mathrm{ICH}$, minor bleeding and no bleeding

\begin{tabular}{|c|c|c|c|}
\hline & ICH or major bleeding, $n=7$ & Minor bleeding, $\mathrm{n}=7$ & No bleeding, $\mathrm{n}=22$ \\
\hline Age (years)* & $69(63-72)$ & $67(61-78)$ & $70(62-79)$ \\
\hline Sex; men & $7(100 \%)$ & $5(70 \%)$ & $16(73 \%)$ \\
\hline Earlier fibrinolysis & 0 & $3(43 \%)$ & $6(27 \%)$ \\
\hline Contraindication for fibrinolysis (other than warfarin) & $1(14 \%)$ & 0 & $3(18 \%)$ \\
\hline Systolic BP* & $126(105-141)$ & $127(90-140)$ & $122(111-140)$ \\
\hline Diastolic BP* & $64(61-92)$ & $69(60-81)$ & $76(70-90)$ \\
\hline \multicolumn{4}{|l|}{ Fibrinolytic agent } \\
\hline streptokinase & $1(14.3 \%)$ & 0 & $5(23 \%)$ \\
\hline tPA (alteplase) & $1(14.3 \%)$ & $1(14.3 \%)$ & $1(4.5 \%)$ \\
\hline reteplase & $5(71.4 \%)$ & $5(71.4 \%)$ & $13(59 \%)$ \\
\hline tenecteplase & 0 & $1(14.3 \%)$ & $3(13.5 \%)$ \\
\hline \multicolumn{4}{|l|}{ Adjuvant medication } \\
\hline aspirin & $1(14 \%)$ & $3(43 \%)$ & $15(68 \%)$ \\
\hline heparin & $5(71 \%)$ & $5(71 \%)$ & $14(64 \%)$ \\
\hline UFH & $3(43 \%)$ & $1(14 \%)$ & $2(9 \%)$ \\
\hline LMWH & $2(29 \%)$ & $4(57 \%)$ & $12(55 \%)$ \\
\hline LMWH (i.v.+s.c.) & $1(14 \%)$ & $2(29 \%)$ & $3(14 \%)$ \\
\hline LMWH only i.v. & $1(14 \%)$ & $2(29 \%)$ & $6(27 \%)$ \\
\hline LMWH reduced dose s.c & 0 & 0 & $3(14 \%)$ \\
\hline \multicolumn{4}{|l|}{ Laboratory parameters at hospital arrival } \\
\hline thrombocytes $\left(\times 10^{9} /\right)^{*}$ & $168(144-191)$ & $205(165-227)$ & $161(134-188)$ \\
\hline haemoglobin $(\mathrm{g} / \mathrm{l})^{*}$ & $153(133-163)$ & $145(139-155)$ & $136(125-141)$ \\
\hline \multicolumn{4}{|l|}{ Survival } \\
\hline hospital discharge & $5(71 \%)$ & $5(71 \%)$ & $16(73 \%)$ \\
\hline 30 days & $5(71 \%)$ & $5(71 \%)$ & $14(64 \%)$ \\
\hline 1 year & $5(71 \%)$ & $4(57 \%)$ & $13(59 \%)$ \\
\hline
\end{tabular}

* = median value (IQR), ICH = intracranial haemorrhage, $\mathrm{BP}=$ blood pressure, UFH = unfractionated heparin, $\mathrm{LMWH}=$ low molecular weight heparin, i.v. = intravenously, s.c. = subcutaneously. 


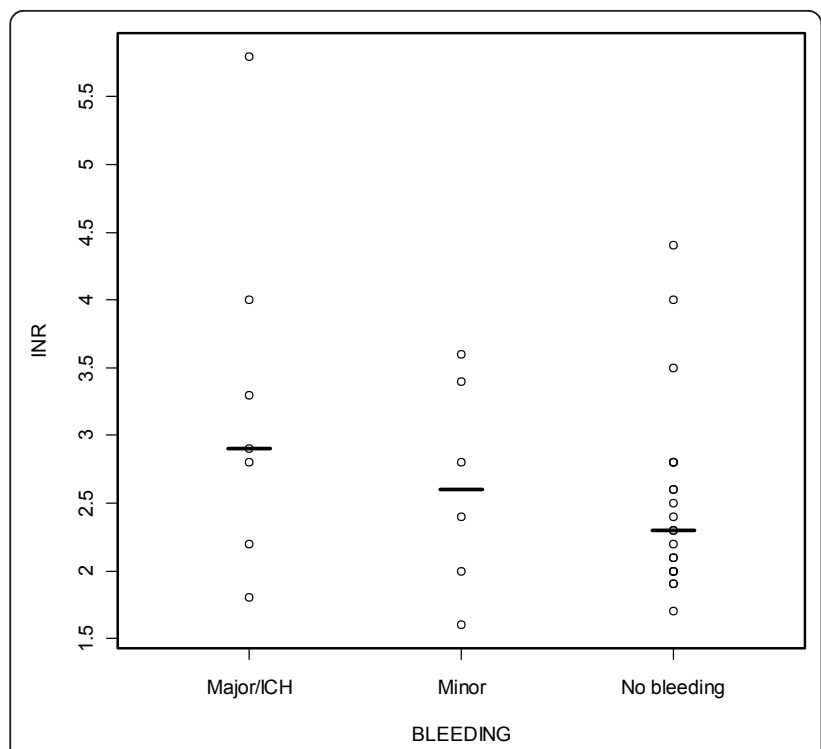

Figure 1 Individual and median INR values with $\mathrm{ICH} /$ major, minor and no-bleeding groups. Median INR for $\mathrm{ICH} /$ major bleeding group was 2,9 (IQR 2,5-3,7), for minor bleeding group 2,6 (IQR 1,9-3,5) and for no-bleeding group 2,3 (IQR 2,0-2,8).

fibrinolytic agents (Table 2). A trend toward increasing bleeding rates with high INR existed: median INR was 2.9 with ICH or major bleeding patients, when nobleeding patients' median INR was 2.3 (Figure 1). With INR-value $2-3$, 18\% (95\% CI 5-42\%) had a severe bleeding complication ( $\mathrm{ICH} /$ major bleeding), whereas $38 \%$ (95\% CI 13-70\%) had a severe bleeding with INR $>3$. Statistical correlation between INR and bleedings was not found.

\section{Survival}

Chest pain was relieved or ceased in 26 (72\%, 95\% CI $56-84 \%)$ patients before hospital admission and STsegment elevation diminished over 50\% 60-90 min after fibrinolysis with 25 (69\%, 95\% CI 53-82\%) patients. Two (6\%, 95\% CI 1-19\%) patients went into cardiac arrest on scene after fibrinolysis. One of them died before hospital admission. One bleeding complication, ICH, was fatal. Thirty-day mortality was almost equal to 1-year mortality (Table 2).

\section{Discussion}

Bleedings occurred frequently after fibrinolysis with patients on warfarin. Major bleeding or $\mathrm{ICH}$ occurred in 7 (19\%, 95\% CI 9-35\%) patients in our study population. Only one of the bleedings, i.e. ICH, was fatal.

Previously major bleeding - according to Thrombolysis in Myocardial Infarction (TIMI) criteria [6] or requiring blood transfusion - has been reported to occur in $2.3 \%$ to $8.3 \%$ of patients receiving fibrinolysis [7-9]. Gusto III study consisting of over 15000 patients showed the prevalence of major bleeding with reteplase and alteplase to be $5.9 \%$ and $6.2 \%$, respectively [10]. Compared to the rates of $\mathrm{ICH}$ with non-warfarin patients receiving fibrinolysis in other studies (0.2-2.6\%) [8-15], anticoagulated patients had slightly higher probability for ICH (3\%, 95\% CI $0-15 \%)$ in our study. According to Helsinki Fibrinolysis Registry the prevalence of fatal ICH after pre-hospital fibrinolysis in patients with suspected STEMI not receiving warfarin was $1 \%(5 / 539,95 \%$ CI $0-2 \%)$ between 1997-2002 (unpublished registry data). Prevalence of spontaneous $\mathrm{ICH}$ and major bleeding in warfarin patients has been reported to be $0.25 \%$ and $1.1 \%$ yearly in a previous study [16].

Only a few studies concerning the use of fibrinolytic agents in anticoagulated patients are available. Stanley et al did not find significant difference in serious complications between warfarin and non-warfarin patients bleeding complications after fibrinolysis, but there was a trend towards a greater prevalence of serious bleedings with anticoagulated patients [17]. Their anticoagulated fibrinolysis patients' rate of any bleeding (4\%) was noteworthy lower than we found in our material, but their amount of $\mathrm{ICH}(4 \%)$ was the same as in our study population (3\%) [17]. Stanley et al found that age, aspirin use and repeated fibrinolysis increases bleeding complications, but in our material no connection between increasing bleeding rates and age or aspirin use appeared. In our study patients receiving aspirin had significantly lower rate of bleedings, but this might be explained by a coincidence or some confounding factors since the size of population was relatively small. Brass and co-workers investigated patients over 65 years old and found that warfarin increased the risk of $\mathrm{ICH}$ only if INR was over 4 [15], while in our population bleedings seemed to increase already with INR-values over 3, but no statistically significant difference existed. Jaegere and co-workers (1992) suggested 3.7-fold higher probability of ICH with patients on anticoagulants [18].

Patients on warfarin suffered from multiple diseases in our unselected "real world setting" study population; ischaemic heart disease and previous myocardial infarctions were common with them, as well as cardiogenic shock or need for CPR. This may partially explain high 30 -days and 1-year mortalities in warfarin patients. Bleeding caused only one death in this group and it does not therefore explain the high mortality.

Although fibrinolysis predisposes patients to bleeding complications, the reported reduction in mortality with pre-hospital fibrinolysis must be taken to consideration. Terkelsen et al reported STEMI patients ' mortalities $(15.4 \% ; 23.3 \% ; 28.1 \% ; 30.8 \%)$ to increase as the delay from emergency dispatching center call to beginning of reperfusion therapy (fibrinolysis or PCI) lengthens 
(0-60 min, 61-120 min, 121-180 min, 181-360 min) [19]. This supports the acceptance of bleeding complication risk with warfarin patients if PCI can not be performed within the recommended time limit (120 min) [3-5]. In identifying the high-risk patients for bleeding, knowing the level of anticoagulation is valuable information. Some of the rapid point-of-care laboratory analysators used in ambulances have the capability to measure INR.

This study is limited by its retrospective nature, small study population, and a lack of a control group. The number of warfarin patients' fibrinolysis reduced notably after year 2004, when Helsinki University Central Hospital of Meilahti started organised PCI treatment for STEMI patients 24 hours daily. Primary PCI is a common therapeutic practice with warfarin patients. Therefore it is difficult to collect a large enough population of warfarin patients treated with fibrinolytic therapy to show significant differences in variables predisposing to bleedings.

Also, several fibrinolytic agents and adjuvants were used over time and therefore linking a certain medication regimen to increased bleeding risk is difficult considering the low number of patients. However, the use of a various medication regimen reflects the changes in clinical practise.

\section{Conclusions}

We conclude that with warfarin patients receiving fibrinolysis, bleedings are common, but only a few of them are fatal. The level of anticoagulation is important knowledge before giving fibrinolysis, because bleedings seem to increase with high INR-values.

\section{Acknowledgements and funding}

None to declare.

\section{Author details}

${ }^{1}$ Helsinki Emergency Medical Service System, Helsinki University Central Hospital, PL 112, 00099 Helsinki City, Helsinki, Finland. ${ }^{2}$ Helsinki EMS Research Group, Helsinki University Central Hospital, PL 112, 00099 Helsinki City, Helsinki, Finland. ${ }^{3}$ Department of Cardiology, Helsinki University Central Hospital of Meilahti, 00290 Helsinki, Finland.

\section{Authors' contributions}

SS has analysed the data and drafted the manuscript. JP has collected the data and has involved in revising the manuscript. JB and TV have given assistance to analysing the data and have revised the manuscript. HL has contributed in collecting the data and revising the manuscript. MK has been a general supervisor and has involved in revising the manuscript and has given the final approval of this article to be considered for publication. All authors read and approved the final manuscript.

\section{Competing interests}

The authors declare that they have no competing interests.

Received: 17 December 2010 Accepted: 5 April 2011 Published: 5 April 2011

\section{References}

1. Björklund E, Stenestrand U, Lindbäck J, Svensson L, Wallentin L, Lindahl B: Pre-hospital thrombolysis delivered by paramedics is associated with reduced time delay and mortality in ambulance-transported real-life patients with ST-elevation myocardial infarction. Eur Heart J 2006, 27:1146-1152.

2. Danchin N, Blanchard D, Steg P, Sauval P, Hanania G, Goldstein P, Camou JP, Guéret P, Vaur L, Boutalbi Y, Genès N, Lablanche JM, USIC 2000 Investigators: Impact of Prehospital Thrombolysis for Acute Myocardial Infarction on 1-Year Outcome. Circulation 2004, 110:1909-1915.

3. Van de Werf F, Bax J, Betriu A, Blomstrom-Lundqvist C, Crea F, Falk V, Filippatos G, Fox K, Huber K, Kastrati A, Rosengren A, Steg PG, Tubaro M, Verheugt $F$, Weidinger $F$, Weis M: Management of acute myocardial infarction in patients presenting with persistent ST-segment elevation. Eur Heart J 2008, 29:2909-2945.

4. Antman EM, Hand M, Armstrong PW, Bates ER, Green LA, Halasyamani LK, Hochman JS, Krumholz HM, Lamas GA, Mullany CJ, Pearle DL, Sloan MA, Smith SC Jr, Anbe DT, Kushner FG, Ornato JP, Pearle DL, Sloan MA, Jacobs AK, Adams CD, Anderson JL, Buller CE, Creager MA, Ettinger SM, Halperin JL, Hunt SA, Lytle BW, Nishimura R, Page RL, Riegel B, Tarkington LG, Yancy CW: 2007 Focused Update of the ACC/AHA 2004 Guidelines for the Management of Patients With ST-Elevation Myocardial Infarction. J Am Coll Cardiol 2008, 51:210-247.

5. Loomba R, Arora R: ST Elevation Myocardial Infarction Guidelines Today: A Systematic Review Exploring Updated ACC/AHA STEMI Guidelines and Their Applications. American Journal of Therapeutics 2009, 16:e7-e13.

6. Bovill E, Terrin M, Stump D, Berke A, Frederick M, Collen D, Feit F, Gore J, Hillis J, Lambrew C, Leiboff R, Mann K, Markis J, Fratt C, Sharkey S, Sopho G, Tracy R, Chesebro J, the TIMI Investigators: Hemorrhagic events during therapy with recombinant tissue-type plasminogen activator, heparin, and aspirin for acute myocardial infarction:results of the Thrombolysis in Myocardial Infarction (TIMI), phase II trial. Ann Intern Med 1991, 115:256-265.

7. López-Sendón J, Dabbous O, López de Sá E, Stiles M, Gore J, Brieger D, van de Werf F, Budaj A, Gurfinkel EP, Fox KA, GRACE Investigators: In-Hospital Outcomes Associated With Fibrinolytic and Thienopyridine Use in Patients With ST-Segment Elevation Acute Myocardial Infarction. The Global Registry of Acute Coronary Events. Rev Esp Cardiol 2009, 62:501-9.

8. Cannon CP, Bahit MC, Haugland JM, Henry TD, Schweiger MJ, McKendall GR, Shah PK, Murphy S, Gibson CM, McCabe CH, Antman EM, Braunwald E: Underutilization of Evidence-Based Medications in Acute ST Elevation Myocardial Infarction Results of the Thrombolysis in Myocardial Infarction (TIMI) 9 Registry. Critical Pathways in Cardiology 2002, 1:44-52.

9. Smalling R, Bode C, Kalbfleisch J, Sen S, Limbourg P, Forycki F, Habib G, Feldman R, Hohnloser S, Seals A: More Rapid, Complete, and Stable Coronary Thrombolysis With Bolus Administration of Reteplase Compared With Alteplase Infusion in Acute Myocardial Infarction. RAPID Investigators. Circulation 1995, 91:2725-32.

10. Topol E: Comparison of Reteplase with Alteplase for Acute Myocardial Infarction. The Global Use of Strategies to Open Occluded Coronary Arteries (GUSTO III) Investigators. N Engl J Med 1997, 337:1118-23.

11. Sabatine M, Morrow D, Montalescot G, Dellborg M, Leiva-Pons J, Keltai M, Murphy S, McCabe C, Gibson M, Cannon C, Antman E, Braunwald E, the Clopidogrel as Adjunctive Reperfusion Therapy (CLARITY)-Thrombolysis in Myocardial Infarction (TIMI) 28 Investigators: Angiographic and Clinical Outcomes in Patients Receiving Low-Molecular-Weight Heparin Versus Unfractionated Heparin in ST-Elevation Myocardial Infarction Treated With Fibrinolytics in the CLARITY-TIMI 28 Trial. Circulation 2005, 112:3846-3854.

12. ISIS-3 (Third International Study of Infarct Survival) Collaborative Group: A randomised comparison of streptokinase vs tissue plasminogen activator vs anistreplase and of aspirin plus heparin vs aspirin alone among 41299 cases of suspected acute myocardial infarction. Lancet 1992, 339:753-70.

13. Bode C, Smalling R, Berg G, Burnett C, Lorch G, Kalbfleisch J, Chernoff R, Christie L, Feldman R, Seals A, Weaver W: Randomized Comparison of Coronary Thrombolysis Achieved With Double-Bolus Reteplase (Recombinant Plasminogen Activator) and Front-Loaded, Accelerated Alteplase (Recombinant Tissue Plasminogen Activator) in Patients With Acute Myocardial Infarction. Circulation 1996, 94:891-8.

14. Gore J, Granger C, Simoons M, Sloan M, Weaver D, White H, Barbash G, Van de Werf F, Aylward P, Topol E, Califf R, the GUSTO-I Investigators: Stroke After Thrombolysis. Mortality and Functional Outcomes in the GUSTO-I Trial. Circulation 1995, 92:2811-2818. 
15. Brass L, Lichtman J, Wang Y, Gurwitz J, Radford M, Krumholz H: Intracranial Hemorrhage Associated With Thrombolytic Therapy for Elderly Patients With Acute Myocardial Infarction: Results From the Cooperative Cardiovascular Project. Stroke 2000, 31:1802-1811.

16. Palareti G, Leali N, Coccheri S, Poggi M, Manotti C, D’Angelo A, Pengo V, Erba N, Moia M, Ciavarella N, Devoto G, Berrettini M, Musolesi S: Bleeding complications of oral anticoagulant treatment: an inception-cohort, prospective collaborative study (ISCOAT). Lancet 1996, 348:423-428.

17. Stanley A, Fletcher S, Tan A, Barnett D: Is warfarin a contraindication to thrombolysis in acute ST elevation myocardial infarction? Heart 2006, 92:1145-1146

18. Jaegere P, Arnold A, Balk A, Simoons M: Intracranial Haemorrhage in Association With Thrombolytic Therapy: Incidence and Clinical Predictive Factors. J Am Coll Cardiol 1992, 19:289-294.

19. Terkelsen C, Sørensen J, Maeng M, Jensen L, Tilsted HH, Trautner S, Vach W, Johnsen SP, Thuesen L, Lassen JF: System Delay and Mortality Among Patients With STEMI Treated With Primary Percutaneous Coronary Intervention. JAMA 2010, 304:763-771.

doi:10.1186/1757-7241-19-21

Cite this article as: Saarinen et al.: Warfarin and fibrinolysis - a

challenging combination: an observational cohort study. Scandinavian Journal of Trauma, Resuscitation and Emergency Medicine 2011 19:21.

\section{Submit your next manuscript to BioMed Central} and take full advantage of:

- Convenient online submission

- Thorough peer review

- No space constraints or color figure charges

- Immediate publication on acceptance

- Inclusion in PubMed, CAS, Scopus and Google Scholar

- Research which is freely available for redistribution

Submit your manuscript at www.biomedcentral.com/submit 